\title{
PROTOTYPE ROBOT MEMANJAT KENDALI MANUAL BERBASIS MIKROKONTROLER ARDUINO MEGA2560
}

\author{
Rahmat Hidayat ${ }^{(1)}$, Zuraidah $^{(1)}$, Jazuli Fadil ${ }^{(1)}$, \\ rahmat hidayat@poliban.ac.id \\ (1) Staf Pengajar Jurusan Téknik Elektro Politeknik Negeri Banjarmasin
}

\begin{abstract}
Ringkasan
Perkembangan ilmu pengetahuan dan teknologi dunia yang sangat pesat saat ini, membutuhkan kreatifitas yang cukup tinggi untuk membuat satu terobosan baru yang dapat diterapkan dalam dunia industri. Salah satunya yaitu dalam penerapan sistem kendali yang banyak dibutuhkan dalam dunia industri dan masyarakat. Banyak peralatan elektronika yang digunakan untuk menggantikan tugas manusia dalam melakukan hal-hal yang berbahaya yang tidak dapat secara langsung dilakukan oleh manusia. Prototype robot kendali manual berbasis mikrokontroler ini digunakan untuk meringankan pekerjaan yang dilakukan oleh manusia. Penggunaan pneumatic yang lebih effisien dan lebih ringan sangat cocok digunakan untuk robot kendali manual. Selain dalam bidang robotika, pneumatic juga banyak digunakan di dunia industri.
\end{abstract}

Kata kunci: sistem kendali, prototype robot, mikrokontroler, dan pneumatic.

\section{A. PENDAHULUAN}

\section{Latar Belakang}

Robotika kini merupakan salah satu bidang yang popular dalam dunia pendidikan, industri, jasa, dan banyak bidang lainnya. Jepang ada-lah salah satu negara yang mengalokasikan da-na sangat besar untuk penelitian dan pengem-bangan robot. Jepang bercita-cita agar setiap rumah di Jepang memiliki satu buah robot. Robot ASHIMO dari Honda merupakan salah satu terobosan produk robotika yang menarik perhatian dunia pada saat pertama kali diluncurkan. Di Indonesia sendiri, bidang robotika mulai berkembang. Namun perkembangan robotika di Indonesia tidak sepesat di Jepang.

Kata robot pertama kali muncul pada tahun 1921 dalam sebuah drama berjudul R.U.R (Rossum's Universal Robot) karangan Karel Capek (dibaca chop'ek). Kata robot berasal dari bahasa Ceko "ROBOTA" yang berarti Forced Labor. Kata "ROBOTICS" berasal dari sebuah karya cerita fiksi ilmiah karangan Issac Asimov pada tahun 1942 yang berjudul "Runaround". Cerita pendek tersebut kemudian dimasukkan oleh Issac Asimov ke dalam buku karangannya yang sangat terkenal "I Robot".

Robot adalah suatu instrumen sistem ken-dali dari sistem-sistem otomatis maupun manual yang dioperasikan dengan program yang telah direncanakan dan mampu mengendalikan pera-latan-peralatan yang sulit dikendalikan dengan tenaga manusia. Peranan robot di zaman sekarang tidak bisa lepas dari dunia industri karena semua instrumen yang digunakan telah dikontrol atau dikendalikan dengan sistem-sistem kendali secara otomatis dan semi otomatis.

Banyak sekali industri yang menggunakan sistem-sistem kendali robot agar lebih memu-dahkan pekerjaan manusia dan lebih memper-cepat pekerjaan yang dilakukan oleh manusia. Contohnya robot yang digunakan untuk memin-dahkan barang, robot untuk pengelasan dan robot untuk melakukan survei ke tempat yang berbahaya. Untuk itu diperlukan pengetahuan tentang bagaimana cara merancang, mengoperasikan, serta membuat sistem kendali dari suatu robot.

\section{Perumusan Masalah}

Secara umum terdapat 3 permasalahan utama dalam pembuatan robot, yaitu perancangan dan pembuatan mekanik robot (body robot), perangkat keras (hardware), dan perangkat lunaknya (software).

1. Dalam perancangan dan pembuatan mekanik meliputi:

a. Perancangan bagian chassis dan lengan robot,

b. Perancangan posisi motor dc pada roda robot,

c. Perancangan posisi pneumatic agar tetap pada posisi lurus, dan

d. Perancangan pemasangan roda.

2. Permasalahan pada perangkat keras (hardware), yaitu :

a. Pembuatan perangkat keras yang dibutuhkan agar robot bisa bekerja termasuk pembuatan rangkaian pembagi 
tegangan, perancangan komunikasi input dari stick PS menuju output, dan

b. Permasalahan error yang selalu ada pada pneumatic ketika stick PS (Play Station) di-tekan.

3. Untuk perangkat lunaknya (software) meliputi:

a. Pemahaman lebih dalam konsep dasar logika bahasa $\mathrm{C}$ pada mikrokontroler arduino mega2560, dan

b. Permasalahan coding pada perintah PWM dengan arduino mega2560.

\section{Batasan Masalah}

Dalam penelitian dibidang robot ini dibatasi sebagaimana berikut:

1. Lapangan (workspace) yang digunakan sudah terkonsep sehingga robot bekerja sesuai dengan prosedur yang diterapkan,

2. Bagian utama hardware yang digunakan pada robot yaitu driver motor, mikrokontroler arduino mega2560, dan driver pneumatic,

3. Pemrograman mikrokontroler menggunakan software arduino dengan bahasa pemrograman bahasa $\mathrm{C}$ dan tidak membahas secara rinci tentang program robot,

4. Secara garis besar tidak membahas spesifikasi motor dc yang digunakan, diameter ban, dan spesifikasi pengeluaran angin pada silinder pneumatic,

5. Jenis robot yang dibahas hanya difokuskan pada cara kerja robot kendali manual.

\section{Tujuan}

Dalam pembuatan penelitian ini terdapat beberapa tujuan, diantaranya adalah :

1. Mengenal dan lebih memahami secara mendalam mikrokontroller arduino mega2560 baik secara teori maupun secara praktek.

2. Mampu menerapkan sistem kontrol arduino mega2560 terhadap robot industri yang akan dibuat.

3. Mampu membuat dan merancang robot yang sering digunakan di dalam dunia industri.

\section{Manfaat}

Adapun manfaat yang didapat dalam penelitian ini adalah

1. Mampu merancang sistem kendali robot dari rancangan mekanik, perangkat keras (hardware) dan perangkat lunak (software).

2. Dapat memahami konsep sistem kendali yang dilakukan secara manual.

3. Mampu merancang sebuah sistem kendali manual pada dunia industri.

4. Mampu menganalisa sistem kendali tersebut jika suatu saat terjadi kerusakan.
5. Sistem kendali robot tersebut nantinya bisa diterapkan di dunia industri dan dunia kerja.

\section{B. LANDASAN TEORI}

\section{Bagian Mekanik}

Bagian mekanik mencakup bagian yang membentuk chassis robot, body robot, lengan robot beserta kelengkapan lainnya agar bisa berfungsi sesuai dengan yang dibutuhkan. Komponen dan peralatan penyusun bagian mekanik robot diberikan sebagai berikut:

\section{Aluminium}

Aluminium atau sejenis besi ringan ini berfungsi untuk menyusun bagian chassis, body dan lengan robot. Aluminium ini-terdiri dari berbagai macam ukuran, mulai dari ukuran $1 \times 1$ Inchi, $1 \times 1 / 2$ Ichi, $1 / 2$ $x 1 / 2$ nchi, $1 / 4 \times 1 / 4$ inchi, dan berbagai macam ukuran lainnya.

\section{Motor DC}

Motor DC disini merupakan perangkat elektromagnetis yang mengubah energi listrik menjadi energi mekanik. Motor DC biasanya digunakan untuk berbagai macam fungsi diantaranya sebagai penggerak roda utama robot dan penggerak lengan naik turun. Motor DC ini menggunakan sumber tegangan $12 \mathrm{~V}$ dan $18 \mathrm{~V}$ dari aki.

\section{Silinder Pneumatic}

Silinder pneumatic pada robot digunakan untuk menjepit beban dan untuk gerakan mekanik lainnya seperti melipat dan mendorong beban pada track. Silinder pneumatic terletak pada beberapa bagian di lengan robot. Silinder pneumatic ini akan bekerja jika salah satu terminalnya diberikan tekanan udara. Udara disimpan di dalam botol bertekanan yang terdapat pada robot. Selang pada botol dialirkan ke solenoid valve dan dialirkan lagi ke masing-masing terminal pada silinder pneumatic. Agar silinder pneumatic bekerja solenoid valve harus dipicu menggunakan tegangan $24 \mathrm{~V}$, sehingga udara bertekanan pada botol yang terhubung ke solenoid valve bisa dialirkan ke terminal silinder pneumatic. Silinder pneumatic memiliki berbagai macam ukuran, namun yang digunakan dalam penelitian ini berukuran $10 \mathrm{~cm}, 15 \mathrm{~cm}$, sedangkan yang terpanjang berukuran 30 $\mathrm{cm}$.

4. Katup dan Flow Control

Katup pada pneumatic adalah penghu bung yang berfungsi sebagai masukan dan keluaran angin pada pneumatic, sedangkan flow control berfungsi untuk 
mengontrol besar kecilnya tekanan angin yang masuk pada silinder pneumatic.

\section{Bagian Hardware}

Bagian hardware merupakan bagian yang berfungsi sebagai catu daya motor, rangkaian pengendali putaran motor (driver motor), rangkaian pengendali gerakan robot, dan berbagai macam fungsi lain. Komponenkomponen dan rangkaian penyusun bagian hardware robot tersebut adalah sebagai berikut:

1. Transistor

Fungsi transistor yaitu untuk menguatkan arus pada rangkaian dan sebagai switching secara otomatis. Transistor dibagi menjadi dua jenis, yaitu jenis NPN dan PNP. Untuk transistor berjenis NPN, kaki basis harus dipicu tegangan dibawah $5 \mathrm{~V}$ untuk membuatnya bekerja, sedangkan jenis PNP kaki basis harus dipicu tegangan $0 \quad \mathrm{~V}$ untuk dapat membuatnya bekerja.

2. IC (Integrated Circuit)

IC merupakan rangkaian gabungan dari sejumlah komponen menjadi satu. Dalam IC monolithic, suatu chip tunggal merupakan dasar komponen individual yang dipadukan dengan sejumlah chip atau komponen lain. Jenis IC pun ada berbagai macam, contohnya IC penurun tegangan (IC 7812, 7809, 7805), IC pendeksi suhu (IC LM35), IC opamp (IC LM339N) dan sebagainya.

3. Relai

Relai merupakan komponen switching tegangan tinggi secara otomatis. Relai biasanya terdiri dari 5 kaki yang masingmasingnya terdiri dari 2 buah kaki coil, kaki common, kaki NO, dan kaki NC. Prinsip kerjanya, apabila coil pada relai mendapat tegangan, maka switch yang tadinya berada di kaki NC akan berubah ke kaki NO, sehingga semua jalur rangkaian yang berada di kaki NO akan hidup dan mendapat tegangan.

4. Switch Push Button dan Switch Toggle Switch push button dan switch toggle memiliki fungsi yang sama, yaitu sebagai switch penghubung jalur sementara yang dihubungkan secara manual. Selain penghubung jalur sementara, push button dan switch toggle juga berfungsi sebagai pengaman rangkaian jika ada arus yang terlalu besar akan masuk. Perbedaan keduanya yaitu pada push button, arus listrik hanya bisa lewat selama push button ditekan, jika tidak ditekan maka arus lisltrik tidak bisa lewat menuju ke rangkaian, sedangkan pada switch toggle, arus listrik bisa lewat selama switch toggle diposisikan ke posisi ON, dan jika posisinya menunjuk pada OFF, maka arus listrik tidak bisa lewat.

\section{Limit Switch}

Fungsi Limit Switch hampir sama seperti switch push button, yaitu sebagai switch penghubung jalur sementara yang dihubungkan secara manual. Akan tetapi limit switch difungsikan agak berbeda dari switch biasa, yaitu sebagai sensor manual yang diletakkan dibagian atas dan bawah chassis robot. Saat limit switch tersentuh lengan robot maka limit akan bekerja sehingga jalur rangkaian yang tadinya hubung akan terputus sehingga gerakan lengan robot berhenti. Limit switch memiliki 3 kaki utama, yaitu kaki common, kaki NO (Normally Open) dan kaki NC (Normally Close). Cara kerjanya yaitu jika limit switch ditekan maka kaki NO akan berubah posisi menjadi kaki NC dan sebaliknya, kaki NC akan berubah posisi menjadi NO.

\section{Bagian Software}

Pada bagian software, robot ini menggunakan algoritma input output untuk memproses data pada mikrokontrolernya. Setiap penekanan tombol pada stick kendali akan selalu dibaca dan diproses oleh mikrokontroler yang kemudian dioutputkan menuju driver motor agar motor dc pada lengan dan roda utama dapat bekerja. Pada gambar 1 berikut, diberikan blok diagram proses kerja software pada robot kendali manual.

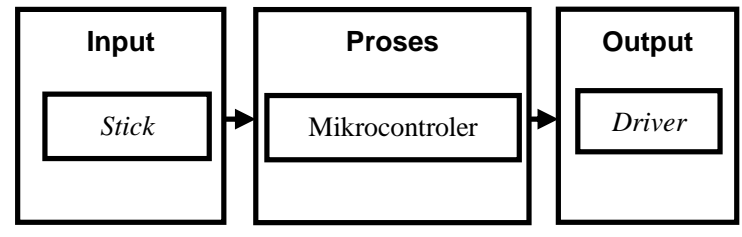

Gambar 1. Proses algoritma pada kendali robot

\section{METODE PENELITIAN}

\section{Rancangan Hardware}

1. Mikrokontroler Arduino Mega2560

Arduino Mega2560 adalah papan mikrokontroler berbasiskan ATmega2560. Arduino Mega2560 memiliki 54 pin digital input/output, dimana 15 pin dapat digunakan sebagai output PWM, 16 pin sebagai input 
analog, dan 4 pin sebagai UART (port serial hardware), $16 \mathrm{MHz}$ kristal osilator, koneksi USB, jack power, header ICSP, dan tombol reset. Ini semua yang diperlukan untuk mendukung mikrokontroler. Dengan menghubungkan mikrokontroller tersebut pada komputer melalui kabel USB maka mikrokontroller tersebut bisa diaktifkan.

2. Skematik mikrokontroler dengan driver motor dc

Driver motor berfungsi sebagai pemberi tegangan menuju ke motor dc sehingga motor tersebut dapat bergerak. Pada robot ini, digunakan 2 jenis driver motor untuk mengendalikan semua motornya, yaitu driver PWM EMS 30A H-Bridge. Driver PWM EMS 30A H-Bridge merupakan driver $\mathrm{H}$-Bridge berbasis IC VNH3SP30 yang didesain untuk menghasilkan drive 2 arah dengan arus konti-nu sampai dengan $30 \mathrm{~A}$ pada tegangan 5,5 volt sampai 36 volt.

Pin input dan output pada arduino,yang digunakan untuk mengontrol PWM motor dengan menggunakan driver motor EMS 30A $\mathrm{H}$-bridge. Skematik mikrokontroler dengan driver motor ini diberikan sebagaimana gambar 2.

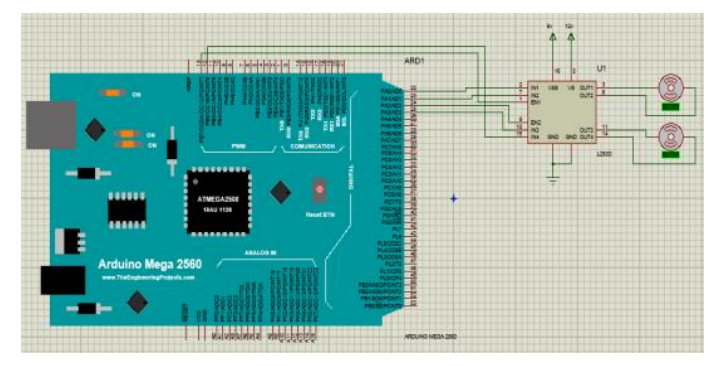

Gambar 2. Skematik mikrokontroller dan driver motor

Sejumlah pin arduino yang di gunakan untuk mengontrol driver motor untuk jalan robot diberikan pada tabel 1.

Tabel 1. Pin input arduino ke driver motor

\begin{tabular}{|c|c|c|}
\hline $\begin{array}{c}\text { Pin } \\
\text { arduino }\end{array}$ & $\begin{array}{c}\text { Driver } \\
\text { motor }\end{array}$ & Keterangan \\
\hline \hline Pin 13 & EN 1 & Mengatur PWM Motor 1 \\
\hline Pin 12 & EN 2 & Mengatur PWM Motor 2 \\
\hline Pin 22 & IN 1 & Mengatur putaran motor 1 \\
\hline Pin 23 & IN 2 & Mengatur putaran motor 1 \\
\hline Pin 24 & IN 3 & Mengatur arah putaran motor 2 \\
\hline Pin 25 & IN 4 & Mengatur arah putaran motor 2 \\
\hline
\end{tabular}

3. Skematik mikrokontroler dengan driver pneumatic
Prinsip kerja dari solenoid valve/katup (valve) solenoida yaitu apabila koil mendapat supply tegangan maka koil tersebut akan berubah menjadi medan magnet sehingga menggerakan plunger pada bagian dalamnya. Ketika-plunger berpindah posisi maka pada lubang keluaran dari solenoid valve pneumatic akan mengeluarkan udara bertekanan yang berasal dari supply (service unit). Solenoid valve pneumatic yang digunakan disini mempunyai tegangan kerja 24V DC.

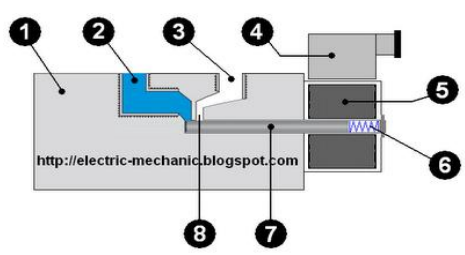

Gambar 3. Struktur Fungsi Solenoid Valve Pneumatic

Berikut keterangan gambar solenoid valve pneumatic.

1. Valve body

2. Terminal masukan (inlet port)

3. Terminal keluaran (outlet port)

4. Terminal slot power suplai tegangan

5. Kumparan gulungan (koil)

6. Spring

7. Plunger

8. Lubang / exhaust

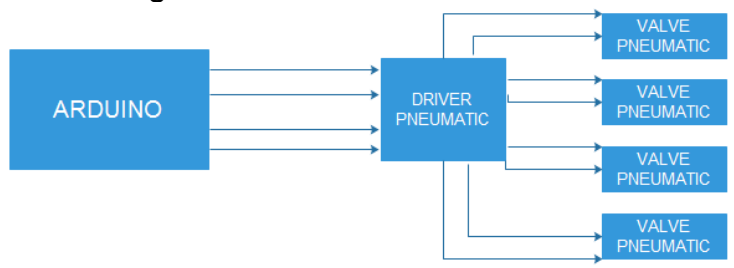

Gambar 4. Skematik mikrokontroler driver pneumatic

Sejumlah pin pada arduino yang digunakan untuk mengontrol valve pneumatic melalui driver pneumatic diberikan pada tabel 2.

Tabel 2. input mikrokontroler driver pneumatic

\begin{tabular}{|c|l|}
\hline Pin input & \multicolumn{1}{|c|}{ keterangan } \\
\hline pin 30 & $\begin{array}{l}\text { sebagai input control driver pneumatic } \\
\text { lengan atas }\end{array}$ \\
\hline pin 31 & $\begin{array}{l}\text { sebagai input driver pneumatic lengan } \\
\text { tengah }\end{array}$ \\
\hline pin 32 & $\begin{array}{l}\text { sebagai input driver pneumatic lengan } \\
\text { bawah }\end{array}$ \\
\hline pin 33 & $\begin{array}{l}\text { sebagai input driver pneumatic lengan } \\
\text { kipas }\end{array}$ \\
\hline
\end{tabular}

4. Rancangan stick kendali

Stick kendali digunakan sebagai pengontrol utama pergerakan robot. Stick ini 
merupakan inputan untuk sistem kendali robot dengan mikrokontroler atmega8535 sebagai prosesor, driver motor sebagai output pergerakan robot, dan solenoid valve sebagai output pergerakan pneumatic. Jumlah tombol yang dipakai pada stick ini berjumlah 16 buah. Pada tabel 3 berikut diberikan fungsi-fungsi tombol yang digunakan untuk menggerakkan robot kendali manual.

Tabel 3. Fungsi-fungsi tombol pada stick kendali

\begin{tabular}{|c|c|}
\hline Tombol & Fungsi \\
\hline R1 & Lengan penjepit tengah naik \\
\hline $\mathrm{R} 2$ & Lengan lengan penjepit tengah turun \\
\hline L1 & Lengan propeller memasang \\
\hline L2 & Lengan propeller melepas \\
\hline$\Delta$ & Lengan atas buka/jepit \\
\hline$\square$ & Lengan tengah jepit/buka \\
\hline$\overline{3}$ & Lengan bawah jepit/buka \\
\hline 4 & Robot bergerak maju \\
\hline$\rightarrow$ & Robot bergerak ke kanan \\
\hline$\downarrow$ & Robot bergerak mundur \\
\hline$\leftarrow$ & Robot bergerak ke kiri \\
\hline SELECT & Gerak naik Lengan propeller \\
\hline START & Gerak turun lengan propeller \\
\hline
\end{tabular}

Pada gambar 4 diberikan blok diagram bagian hardware dari robot kendali manual.

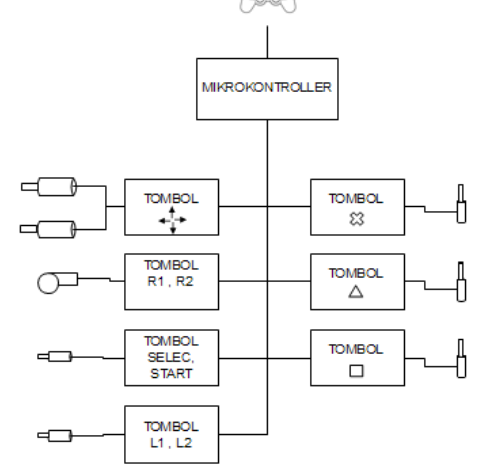

Gambar 5. Blok diagram kendali robot

Prinsip kerja dari blok diagram diatas adalah ketika tombol pada stick kendali ditekan, stick kendali akan memberikan inputan dengan logika tertentu pada mikrokontroler Arduino Mega2560 sehingga mikrokontroler dapat memproses data input yang diberikan. Setelah data tersebut diproses dalam mikrokontroler, data output akan menuju driver motor yang kemudian akan memberikan tegangan pada motor dc sehingga motor dc pada roda utama dan lengan robot dapat bergerak. Selain dari itu juga akan memicu solenoid valve sehingga pneumatic dapat bekerja. Pada tabel 4 diberikan sejumlah pin output dari mikrokontroler yang terhubung ke pin masingmasing hardware dan stick PS.

Tabel 4. Pin dan output pada mikrokontroler

\begin{tabular}{|c|c|}
\hline Pin & Output \\
\hline \hline 7 & PWM motor dc 1 \\
\hline 6 & PWM motor dc 2 \\
\hline 5 & PWM motor dc 3 \\
\hline 4 & PWM motor dc 4 \\
\hline 3 & PWM motor dc power window 5 \\
\hline 22 & Arah putaran motor 1 kanan \\
\hline 23 & Arah putaran motor 1 kiri \\
\hline 24 & Arah putaran motor 2 kanan \\
\hline 25 & Arah putaran motor 2 kiri \\
\hline 26 & Arah putaran motor 3 kanan \\
\hline 27 & Arah putaran motor 3 kiri \\
\hline 28 & Arah putaran motor 4 kanan \\
\hline 29 & Arah putaran motor 4 kiri \\
\hline 30 & Arah putaran motor 5 kanan \\
\hline 31 & Arah putaran motor 5 kiri \\
\hline 38 & Valve pneumatic 1 \\
\hline 40 & Valve pneumatic 2 \\
\hline 41 & Valve pneumatic 3 \\
\hline 42 & Valve pneumatic 4 \\
\hline 14 & Clock stick PS \\
\hline 15 & Command stick PS \\
\hline 16 & Attention stick PS \\
\hline 17 & Data stick PS \\
\hline 48 & Motor pasang propeller \\
\hline 49 & Motor lepas propeller \\
\hline & \\
\hline
\end{tabular}

\section{Rancangan Software}

Bagian software merupakan bagian yang berfungsi untuk mengatur kerja dan gerakan robot mulai dari gerakan secara otomatis sampai gerakan yang dikendalikan melalui joystick/stick PS. Dalam perakitan robot, bagian software biasanya adalah program untuk membuat gerakan-gerakan robot. Jika program telah selesai dibuat, program tersebut akan diisikan ke dalam chip dari robot yang kemudian robot akan dilihat pergerakannya. Jika pergerakannya sudah sesuai dengan yang diinginkan maka program dikatakan telah berhasil, tetapi jika per-gerakannya belum sesuai atau masih ada error maka program akan diperbaiki sampai pergerakan robotnya telah sesuai dengan yang diinginkan.

Bahasa pemrograman yang dipakai untuk memprogram robot ini menggunakan bahasa $\mathrm{C}$ sedangkan software yang dipakai untuk membuat program beserta program simulasinya adalah program Arduino.

\section{HASIL DAN PEMBAHASAN}

\section{Hasil dan Pembahasan Robot}

Untuk pembahasan robot kendali diberikan tiga pembahasan rancangan utama untuk mengetahui hasil yang maksimal, yaitu pada rancangan bagian mekanik, rancangan pada bagian hardware dan rancangan pada bagian software sebagai berikut: 
1. Hasil rancangan mekanik robot

a. Penambahan tabung udara pneumatic

Penambahan tabung udara pneumatic dilakukan untuk mendapatkan hasil yang sesuai dengan harapan awal yaitu membuat agar robot mampu melakukan lebih banyak gerakan mekanik yang memerlukan pneumatic. Dengan penambahan tabung udara ini, performa gerakan mekanik robot menjadi lebih maksimal sebagaimana diberikan pada gambar 6.

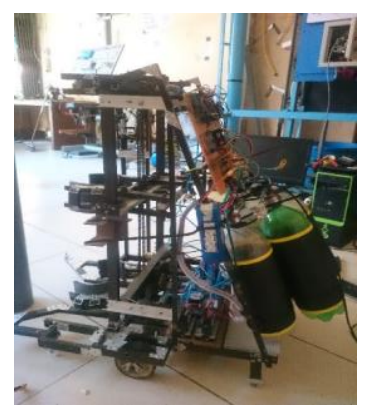

Gambar 6. Perubahan desain robot

b. Peletakkan silinder pneumatic, selang dan botol.

Peletakkan silinder pneumatic sangat penting karena posisi silinder pneumatic harus dalam keadaan lurus. Banyak hal yang dapat terjadi jika peletakkan silinder pneumatic tidak dalam keadaan lurus, salah satunya menyebabkan kebocoran pada karet pada silinder sehingga angin akan merembes keluar. Hal itu menyebabkan piston tidak dapat bekerja maksimal bahkan dapat menyebabkan silinder tidak bekerja sama sekali. Selang yang digunakan pada robot kendali manual berukuran $6 \mathrm{~mm}$ sedangkan botol yang digunakan adalah botol minuman bersoda berukuran 3L. Dalam penelitian ini digunakan 15 botol sebagai penampung angin dari compressor —dengan tekanan anginnya sebesar 6-8 bar. Selang yang dipakai dipasang secara seri dengan tujuan agar angin dalam masing-masing botol tersebut dapat saling berhubungan satu sama lain.

\section{c. Hasil kerja sistem robot}

Untuk kerja sistem robot kendali manual, gerak robot manual mengikuti perintah dari operator dengan menggunakan stick kendali, kemudian robot akan membawa dan meletakkan objek (propeller) memasang kebagian atas tiang sebagaimana diberikan pada gambar.

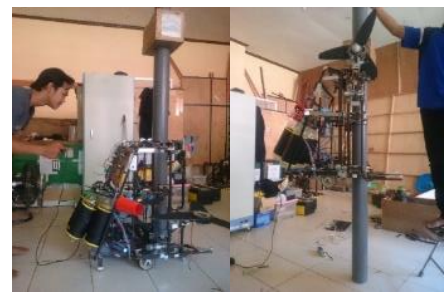

Gambar 7. Robot meletakkan propeller

2. Hasil Rancangan Hardware

a. Mikrokontroler arduino mega2560

Digunakannya mikrokontroler arduino Mega25605 dikarenakan bentuknya yang minimalis dan sesuai dengan ukuran tempat yang tersedia pada robot. Robot ini menggunakan arduino mega2560 karena sangat cocok digunakan pada robot kendali manual dengan jumlah port yang banyak sehingga sangat mencukupi.

\section{b. Driver motor 30 EMS H - Bridge}

Pada robot kendali manual digunakan driver 30 EMS H-Bridge sebagai driver untuk mengontrol motor utama dan penggerak motor dc power windows untuk turun naik lengan robot karena driver motor ini memiliki ampere yang besar, yakni 30A.

\section{c. Solenoid valve pneumatic}

Solenoid valve pneumatic merupakan salah satu bagian penting dari sebuah sistem pneumatic, karena solenoid pneumatic ini berfungsi sebagai switch ON-OFF untuk menggerakkan cylinder pneumatic dengan valve ini mempermudah pengon trolan pneumatic.

\section{d. Switching}

Driver pneumatic ini menggunakan transistor PNP yang berfungsi untuk menguatkan arus dan switching manual dari rangkaian. Sedangkan dan dioda digunakan agar arus listrik mengalir dalam suatu arah (panjar maju) dan untuk menahan arus dari arah sebaliknya (panjar mundur). Basis dalam rangkaian ini berfungsi untuk picuan pneumatic, collector untuk positif (24V) sedangkan emitor untuk negatif (OV).

\section{Software}

a. Bagian program robot di mikrokontroller.

Program robot kendali manual dilakukan dengan melakukan pemanggilan library, pengaturan konfigurasi input/output program, pengaturan konfigurasi Timer 1 untuk PWM. Perintah utama dari robot kendali manual di mikrokontroller adalah untuk mengatur :

1) input motor power window 
2) input motor jalan robot

3) valve lengan jepit atas

4) valve lengan jepit tengah

5) valve lengan jepit bawah

6) input motor lengan propeller

\section{Hasil Panjat Robot}

Pengujian robot saat memanjat tiang diperoleh hasil sebagai berikut:

Tabel 5. Hasil panjatan robot

\begin{tabular}{|c|c|c|c|}
\hline $\begin{array}{c}\text { Tinggi Tiang } \\
(\mathrm{cm})\end{array}$ & $\begin{array}{c}\text { Berat Robot } \\
(\mathrm{kg})\end{array}$ & $\begin{array}{c}\text { Tekanan Angin } \\
(\mathrm{bar})\end{array}$ & Waktu \\
\hline \hline $150 \mathrm{~cm}$ & $20,8 \mathrm{~kg}$ & $6 \mathrm{bar}$ & 30 detik \\
\hline $150 \mathrm{~cm}$ & $20,8 \mathrm{~kg}$ & $5 \mathrm{bar}$ & 40 detik \\
\hline $150 \mathrm{~cm}$ & $20,8 \mathrm{~kg}$ & $4 \mathrm{bar}$ & 60 detik \\
\hline $240 \mathrm{~cm}$ & $20,8 \mathrm{~kg}$ & $6 \mathrm{bar}$ & 45 detik \\
\hline $240 \mathrm{~cm}$ & $20,8 \mathrm{~kg}$ & 4 bar & 1,5 menit \\
\hline
\end{tabular}

Dari hasil mengujian panjatan robot didapat hasil

1. Saat tekanan udara pada robot 6 bar kinerja kerja robot maksimal saat menjepit tiang.

2. Saat tekanan udara pada robot 5 bar kinerja kerja robot kurang maksimal dikarenakan kekuatan lengan saat menjepit kurang kuat.

3. Saat tekanan udara pada robot 4 bar kinerja kerja robot tidak maksimal dikarenakan cengkraman lengan ke tiang tidak kuat, dan mengakibatkan robot terturun/tergelincir.

Dari hasil percobaan, tekanan udara sangat berpengaruh terhadap kinerja panjatan robot, dimana tekanan udara harus selalu dicek agar tekanan bisa stabil pada kisaran 6-5 bar sehingga kinerja robot bisa maksimal.

\section{E. PENUTUP}

\section{Kesimpulan}

Dari tahapan pengujian robot kendali manual yang telah dilakukan, maka dapat diambil kesimpulan, yaitu :

1. Untuk sumber tegangan pada motor utama ataupun pada motor dc power windows tidak dapat digabung dengan sumber tegangan untuk pneumatic.

2. Pemakaian sistem pneumatic dapat mempermudah dan mempercepat kerja robot.

3. Penempatan silinder pneumatic sangat berpengaruh dengan aliran angin yang disalurkan.

4. Mikrokontroler Arduino Mega2560 sebagai pusat kontrol (prosesor) yang berisi fitur-fitur yang lengkap dan sangat mudah untuk diprogram sehingga sangat cocok untuk diaplikasikan kedalam suatu alat elektronik.
5. Pengaturan nilai PWM kedua driver sangat berpengaruh dengan pergerakan robot.

\section{F. DAFTAR PUSTAKA}

1. Brian, W. Evans, 2007. Arduino Programming Notebook, Graha IImu, Yogyakarta.

2. Ecadio, 2015. Mengenal Arduino Mega 2560, Bandung.

3. Saptaji, 2016. Arduino Sebagai (Real Time Lock), Mizan, Bandung.

4. Kadir, Abdul, 2016. Panduan Praktis Mempelajari Mikrokontroller dan Pemrogramannya Menggunakan Arduino, Yogyakarta.

5. Dwi, Taufiq, 2011. Buku Pintar Robotika : Bagaimana Merancang dan Membuat Robot Sendiri, Andi Publisher, Yogyakarta.

6. Sanjaya, Mada, 2016. Panduan Praktis Membuat Robot Cerdas Menggunakan Arduino dan Matlab, Andi Publisher, Yogyakarta. 